\title{
The overestimation of vertical distance and slope and its role in the moon illusion
}

\author{
RICHARD KAMMANN 1 \\ OAKLAND UNIVERSITY
}

Six experiments were conducted to test the hypothesis that overestimation of vertical distance is a pervasive phenomenon. The experiments involved judgments of: (a) vertical distance looking upward; (b) vertical distance looking downward; (c) the slope of a real hill; (d) the recalled slopes of streets; (e) the magnitudes of angles drawn on paper; (f) the distances to afterimages projected into the sky. The results showed that a very strong illusion of overestimation of both vertical distance and slope occurred in all situations except for the judgments of drawn angles by males. Furthermore, in five of the six experiments females showed a greater amount of the illusion than males. The discussion pointed out the difficulty of explaining the moon illusion by the assumptions of a flattened sky surface and Emmert's law in light of the data.

At present there exist two tenable theories of the moon illusion whtch, however, make opposite assumptions about the perception of distances in vertical or elevated directions. The theory of Kaufman and Rock (1962) assumes that, perceptually speaking, the sky is a surface which has the shape of a "flattened dome." This phrase indicates that the sky surface is perceived to be farther away at the horizon than when it is overhead as a result of the visible terrain. The larger apparent size of the moon (or sun) at the horizon is derived from this greater apparent distance, by the logic of Emmert's law for afterimages. ${ }^{2}$ This same argument was advanced by King and Gruber (1962) who showed that the size illusion also held for negative afterimages projected into the sky at the horizon and at $45 \mathrm{deg}$ elevation.

However, Thor and Wood (1966) have taken the position that vertical distances are typically overestimated relative to horizontal distances. This "heightened arch" view of visual space implies that targets at high elevations in the sky are seen as farther away, as well as smaller, which is a direct reversal of the positive correlation of size and distance as given in Emmert's law. Since the sky is not, in fact, a surface with normal cues to its distance, it is not necessary that Emmert's law should apply, even for afterimages. Furthermore, Thor and Wood reported vertical distance overestimation in experiments in both a lighted and darkened room. They concluded from their investigation that the moon illusion is one case of visual distortion produced by stimulation coming from the vestibular system accompanying the tilting of the head.

The purpose of this paper is to report several experiments which were designed to find out how pervasive is the tendency, as suggested by the Thor and Wood hypothesis, for observers to overestimate vertical distances. The present studies examined vertical distance judgments in both upward and downward directions, the perceived and recalled slopes of hills, the magnitudes of drawn angles, and the apparent distances to afterimages projected into the sky. The data were analyzed by the sex of the subject in each situation. Since each experiment measured an apparent vertical distance relative to an apparent horizontal distance, it would be equally possible to call the phenomenon horizontal underestimation, although some anecdotal data could be offered to support the term chosen.

\section{METHODS}

In all of the six experiments run, the Ss were undergraduate students at Oakland University, and except for five female $\mathrm{Ss}$ who participated in Experiments 2,3 , and 6 , no Ss were used in more than one experimental condition. In all experiments requiring target perception, the $S$ was free to use binocular vision under normal indoor or outdoor lighting conditions.

\section{Experiment 1: Distance Upward}

The purpose of this experiment was to replicate and quantify the Thor and Wood report that the distance to the ceiling of a room is overestimated relative to the distance to the wall. The room used had a ceiling height of $13.4 \mathrm{ft}$ (the front of a small classroom auditorium) with cream colored walls and ceiling.

In the first version (a) of the experiment, the $S$ was first shown a plain white paper plate suspended at eye level on the far wall. Directly above this on the ceiling, in a line perpendicular to the wall was mounted a row of eleven identical paper plates. These plates ran from $.90 \mathrm{ft}$ from the wall, at $1.74 \mathrm{ft}$ intervals, to a final distance of $18.30 \mathrm{ft}$ for the 11 th plate. The $\mathrm{S}$ was asked to walk back and forth beneath the row of ceiling plates until he found one to stand under such that the distance from his eyes to the wall plate was equal to the distance from his eyes (emphasized) to the chosen plate on the ceiling. At that time his eye height was measured, and with $.10 \mathrm{ft}$ added to compensate for the upward tilting of the head, the actual distance from eyes to ceiling. could be obtained by subtracting the corrected eye height from the total room height. If the $S$ chose a paper plate which was farther from the wall than the distance from eyes to ceiling, he was said to overestimate the vertical distance accordingly.

In the second version (b) of the experiment, all paper 


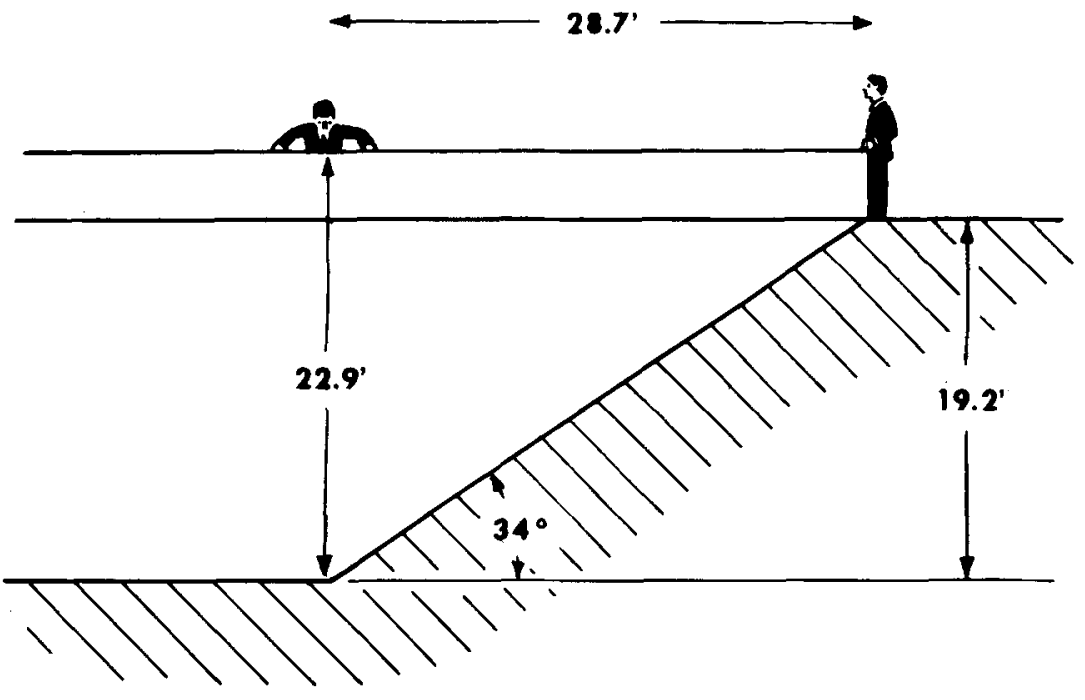

Fig. 1. Diagram of the physical situation for the vertical-horizontal distance comparison in Experiment 2, and of the slope judged in Experiment 3. plates were removed and a path perpendicular to the wall was marked by two chalk lines on the floor. Again each $S$ was asked to walk back and forth in the path until he found a place to stand such that the eye-wall distance matched the eye-ceiling distance. In this case it was necessary to measure not only the S's eye height but also the distance from the wall to his eyes. A different sample of Ss was used in each version of the experiment.

\section{Experiment 2: Distance Downward}

This study examined vertical distance judgments in which the $S$ had to look downward instead of upward. Each $S$ was stationed near the center of a bridge walkway leading from a $19.2 \mathrm{ft}$ hill to the third floor of the Van Wagoner dormitory. The situation is shown in Fig. 1. The $S$ was asked to bend over until his eyes were level with the bridge railing and to observe the distance from his eyes to the ground below (which was level). He was then asked to straighten up and observe the distance to the $\mathrm{E}$ who had taken a position at the open end of the bridge. Ss were encouraged to look down and forth again and then to report which distance was greater. After a choice was made, they were asked "greater by what per cent?" The actual distance from eyes to ground was $22.9 \mathrm{ft}$ and the distance to the $\mathrm{E}$ was $28.7 \mathrm{ft}$, for a physical vertical-horizontal distance ratio of .80 .

\section{Experiment 3: The Slope of a $34^{\circ} \mathrm{Hill}$}

It followed that if the Ss overestimated the vertical distance from the bridge to the ground in Experiment 2, they should also overestimate the slope of the $34 \mathrm{deg}$ grass hill which fell from bridge level to ground level underneath the forward section of the bridge (Fig. 1 ). In order to ensure that the $S$ understood the judgmental task, he was first shown a line diagram of two hills of $30 \mathrm{deg}$ and $60 \mathrm{deg}$, each labeled only by an arrow and the symbol $\theta$ which identified the angle of interest.
For further anchoring, a 0 deg hill was verbally defined as level ground with no slope and a $90 \mathrm{deg}$ hill as a straight up and down cliff wall. The $S$ was then asked to walk wherever he wished and to report back with his best estimate of the slope of the hill in degrees. No $S$ reported difficulty in understanding the task.

\section{Experiment 4: Memory for Steep Streets}

In order to ensure that the results from Experiment 3 would not be peculiar to that visual scene, a questionnaire was distributed to an introductory psychology class during the first week of the course. The questionnaire showed a line diagram of a hill with the $45 \mathrm{deg}$ angle under the hill numerically labeled. The verbal definitions of $0 \mathrm{deg}$ and $90 \mathrm{deg}$ slopes as in Experiment 3 were included. The questionnaire asked the Ss to report, in degrees, the steepest streets they had ever driven on, walked on, and seen, with the location of the streets requested in each case. Only the data from steepest streets ever driven on are reported here; these data show the least amount of overestimation of the three questions.

In order to calculate the amount of overestimation. it was necessary to decide upon some maximum feasible slope as a baseline, for which purpose 25 deg was decided to be a generous estimate after an examination of several highway engineering manuals which made no reference to grades above $15 \mathrm{deg}$. Furthermore, it was established through the San Francisco Bureau of Engineering, Division of Grades, that the steepest segment of passable street in that city was $17.5 \mathrm{deg}$. Those Ss who located their steepest street experlences in San Francisco were then used as a subsample for comparison with this more objective baseline.

\section{Experiment 5: Judgments of Drawn Angles}

As the result of Experiments 3 and 4 were analyzed, it became an obvious necessity to determine whether or not such Ss were able to use the concept of degrees 
of angle appropriately. Therefore, a control experiment was run in which another introductory psychology class was presented with a random array of six angles (each with a horizontal baseline) on an otherwise unlabeled, mimeographed sheet. The six angles reproduced on each sheet were $10 \mathrm{deg}, 20 \mathrm{deg}, 35 \mathrm{deg}$, $50 \mathrm{deg}, 70 \mathrm{deg}$, and $90 \mathrm{deg}$. With no anchoring definitions offered, the Ss were simply asked to write in the correct number of degrees for each angle shown.

\section{Experiment 6: Distances to Afterimages on the Sky}

It was considered possible that Ss might not only see a difference in the sizes of afterimages projected at different elevations in the sky (King \& Gruber, 1962), but they might also see a difference in apparent distances, thus providing data directly relevant to the applicability of Emmert's law in this situation. Each $\mathrm{S}$ was asked to fixate foveally and binocularly a small white square, subtending $1.3 \mathrm{deg}$ of visual arc, pasted on a very dark blue field. He was then asked to observe the dark afterimage of the square in the sky both over the horizon and at $45 \mathrm{deg}$ elevation (as defined by $\mathrm{S}$ ). The sky was a homogeneous gray-blue field with the sun located over the shoulders on both days the data were collected. The $S$ was then asked in half of the cases which image was larger, and then larger by what percent. Following another fixation period, these Ss were asked to determine which image was farther away, and by what per cent. For the other half of the Ss the two questions were reversed in order.

\section{RESULTS}

The index which seemed to provide the most comparability across the experiments was the ratio of apparent vertical distance to apparent horizontal distance. For example, a mean apparent $V / H$ distance ratio of 1.65 would mean that, on the average, a particular vertical distance seemed to be 65 percent greater than a physically equal horizontal distance in that situation. In Experiment 1 the mean apparent $\mathrm{V} / \mathrm{H}$ ratio was given directly by (a) the distance of the chosen ceiling plate from the wall, or (b) the distance the $S$ stood from the wall-divided by the distance from the wall which would correctly match the distance to the ceiling. In Experiments 2, 3, and 4, the $S$ was not presented with physically equal vertical and horizontal distances so the data had to be corrected by the physical ratio actually presented. In the cases of the slopes of hills (Experiments 3 and 4), the estimated and physical $\mathrm{V} / \mathrm{H}$ ratios were defined by the tangents of the estimated and correct angles, respectively. Finally, in Experiment 6 the ratio given could be called the mean $\mathrm{E} / \mathrm{H}$ ratio since it represented apparent distance to a $45 \mathrm{deg}$ elevated target as compared with the apparent distance to a target just over the horizon; no vertical distance was involved.

The results, according to the sex of the Ss, are given in Table 1; the formulas for calculating the $\mathrm{V} / \mathrm{H}$ ratios are given in the footnotes. It can be seen that in every case both males and females showed vertical overestimation, statistically significant in all but one case which had too small an N. Furthermore, in every case except that of the afterimages in the sky (Experiment 6), the females showed a greater amount of vertical overestimation, which was statistically significant in Experiments 1 to 5. The percent of judgments in all situations which were underestimations, correct, and overestimations were 4.2, 6.4, and 89.4 for males, respectively, and $0.0,2.5$, and 97.5 for females, respectively.

In Experiments 1 and 2 (vertical distances upward and downward) there remained the possibility that the Ss were not using the eyes as a reference point for vertical distance, although the instructions emphasized this point. However, if the Ss used some point nearer their feet as a reference point, it would reduce the calculated illusion in Experiment 1 , but it would increase it in Experiment 2.

In order to interpret the data from Experiments 3 and 4 , both involving estimates of slope, it is necessary

Table 1. Mean Apparent Vertical/Horizontal Distance Ratios in Five Experiments ${ }^{a}$

\begin{tabular}{|c|c|c|c|c|c|c|c|}
\hline \multirow[b]{2}{*}{ Experiment } & \multirow[b]{2}{*}{ Situation } & \multicolumn{2}{|c|}{ Males } & \multicolumn{2}{|c|}{ Females } & \multirow[b]{2}{*}{$t(\operatorname{sex})$} & \multirow{2}{*}{$\begin{array}{l}\text { Signif. } \\
\text { Level }\end{array}$} \\
\hline & & $N$ & V/H Ratio & $\mathrm{N}$ & V/H Ratio & & \\
\hline la. & $\begin{array}{l}\text { Ceiling with paper plates } \\
\text { Ceiling without plates }\end{array}$ & $\begin{array}{l}15 \\
15\end{array}$ & $\begin{array}{l}1.42 * * \\
1.62 * *\end{array}$ & $\begin{array}{l}15 \\
15\end{array}$ & $\begin{array}{l}1.52 * * \\
1.94 * *\end{array}$ & $\begin{array}{l}1.05 \\
3.20\end{array}$ & $\begin{array}{l}\text { N.S. } \\
.01\end{array}$ \\
\hline 2 & $22.9 \mathrm{ft.}$ bridge $\mathrm{e}^{b}$ & 4 & 1.28 & 12 & $1.69 * *$ & 2.34 & .05 \\
\hline 3 & $34^{\circ}$ hill slope ${ }^{c}$ & 66 & $1.65 * *$ & 13 & $2.12 * *$ & 3.53 & .001 \\
\hline $\begin{aligned} & 4 a \\
& \text { b. }\end{aligned}$ & $\begin{array}{l}25^{\circ} \text { street }^{c} \\
17.5^{\circ} \text { street }(\mathrm{SF})^{c}\end{array}$ & $\begin{array}{r}78 \\
4\end{array}$ & $\begin{array}{l}1.71 * * \\
2.48 *\end{array}$ & $\begin{array}{r}92 \\
6\end{array}$ & $\begin{array}{l}2.31 * * \\
4.46 * *\end{array}$ & $\begin{array}{l}5.04 \\
2.12\end{array}$ & $\begin{array}{l}.001 \\
\text { N.S. }\end{array}$ \\
\hline 6. & Images in the sky ${ }^{d}$ & 7 & $1.48 * *$ & 8 & $1.28 *$ & 2.07 & N.S. \\
\hline
\end{tabular}

a. $V / H$ ratios significantly different by $t$ test from a ratio of 1.00 are marked * for the .05 level and ** for the .001 level.

$b$. In experiment 2 the mean estimated $V / H$ ratio was divided by .80 , the physical $V / H$ ratio presented to the $S$.

$\dot{c}$. In Experiments 3 and 4 the $\mathrm{V} / \mathrm{H}$ ratio is the tangent of the mean estimated angle divided by the tangent of the correct or maximum angle of slope $\left(34^{\circ}, 25^{\circ}, 17.5^{\circ}\right.$ ).

d. The $V / H$ ratio in Experiment 6 is the mean of the reported ratios of the distance to the $45^{\circ}$ elevated afterimage to the distance of the horizon afterimage. 
Table 2. Reported Degrees of Angle for Six Drawn Angles ${ }^{a}$ $(N=20$ males, 20 females $)$

\begin{tabular}{|c|c|c|c|c|c|c|}
\hline Measure & $10^{\circ}$ & $20^{\circ}$ & $\begin{array}{l}\text { Draw } \\
35^{\circ}\end{array}$ & $\begin{array}{c}\text { Angles } \\
50^{\circ}\end{array}$ & $70^{\circ}$ & $90^{\circ}$ \\
\hline $\begin{array}{l}\text { Mean (males) } \\
\text { Mean (females) }\end{array}$ & $\begin{array}{l}11.3 * \\
15.0 * *\end{array}$ & $\begin{array}{l}23.5^{*} \\
27.3^{* *}\end{array}$ & $\begin{array}{l}36.3 \\
41.3^{* *}\end{array}$ & $\begin{array}{l}50.5 \\
57.7^{*}\end{array}$ & $\begin{array}{l}73.5 \\
79.0 * *\end{array}$ & $\begin{array}{l}90.0 \\
90.0\end{array}$ \\
\hline $\begin{array}{l}\text { S.D. (males) } \\
\text { S.D. (females) }\end{array}$ & $\begin{array}{l}2.36 \\
3.94\end{array}$ & $\begin{array}{l}4.33 \\
3.94\end{array}$ & $\begin{array}{l}5.90 \\
4.33\end{array}$ & $\begin{array}{r}4.33 \\
10.22\end{array}$ & $\begin{array}{l}8.27 \\
3.15\end{array}$ & $\begin{array}{l}0.00 \\
0.00\end{array}$ \\
\hline $\begin{array}{l}\mathrm{V} / \mathrm{H} \text { Ratio } \\
\text { (males) }^{b} \\
\mathrm{~V} / \mathrm{H} \text { Ratio } \\
{(\text { females })^{b}}^{b}\end{array}$ & 1.11 & 1.19 & 1.04 & 1.02 & 1.23 & - \\
\hline $\begin{array}{l}t(\text { sex diff.) } \\
\text { Signif. level }\end{array}$ & $\begin{array}{l}3.56 \\
.001\end{array}$ & $\begin{array}{r}2.80 \\
.01\end{array}$ & $\begin{array}{r}2.98 \\
.01\end{array}$ & $\begin{array}{r}2.84 \\
.01\end{array}$ & $\begin{array}{r}2.58 \\
.05\end{array}$ & - \\
\hline
\end{tabular}

a. Means of reported angles which are significantly different from the correct angle by $t$ test are marked * for the .0s level and ** for the .001 level.

b. The $V / H$ ratio rejers to the tangent of the mean reported angle divided by the tangent of the correct angle.

to examine the results of the control study on judgments of drawn angles. The results may be seen in Table 2. It will be noted first that the data were stable enough so that even small mean deviations from the correct angle were often significant. In general, males showed a slight overestimation but only for the smaller angles, while females showed a consistent small overestimation of all angles (except $90 \mathrm{deg}$ ). That these differences are not based simply on a greater lack of familiarity with angles by females is probable in that fermales usually showed no greater variability of judgments than males.

Although both overestimation and the sex difference held for drawn angles, the degree of illusion was substantially less than that found in Experiments 3 and 4. For example, a $34 \mathrm{deg}$ hill slope produced mean estimates of $48 \mathrm{deg}$ and $55 \mathrm{deg}$ for males and females, respectively, but a drawn angle of $35 \mathrm{deg}$ produced mean estimates of only $36 \mathrm{deg}$ and $41 \mathrm{deg}$, respectively. Similarly, the estimated maximum street slope of $25 \mathrm{deg}$ (with actual values perhaps in $15 \mathrm{deg}$ to $20 \mathrm{deg}$ range) produced recall estimates of $38 \mathrm{deg}$ and $47 \mathrm{deg}$, while a drawn angle of $20 \mathrm{deg}$ produced recall estimates of only $23 \mathrm{deg}$ and $27 \mathrm{deg}$ for males and females, respectively. All considered, the data seem to say that the illusion holds to some degree even for drawn angles, rather than seeming to say that the Ss simply don't know how to use the concept of degrees of angle.

In Experiment 6 (afterimages in the sky) the size judgments, not appearing in Table 1 , revealed that the images appeared larger on the horizon than at elevation, just as with the moon. The illusion for males, with a horizontal-to-elevated size ratio of 1.44 , was comparable to that found by King and Gruber, but for females, it was substantially less $(1.17)$.

\section{DISCUSSION}

An obvious question is whether the various judgmental tasks used in this study involved the same perceptual processes. The judgment of distances in Experi- ments 1,2, and 6, involved comparisons of distances along the line of sight with the observer's eyes as a point of origin. In the judgments of slopes and drawn angles the relevant distances were between external points, may have varied from parallel to perpendicular to the line of sight (as for a hill viewed from the front versus from the side), and did not necessarily involve head tilt.

The results are tentatively placed together here because of the geometric consistency by analyzing slopes into their vertical and horizontal components and because the sex difference was consistent in all situations except Experiment 6 (afterimages on the sky). Given these considerations it is less easy to find an acceptable alternative classification for the tasks. For example, the overestimation of drawn angles could be easily subsumed under the classical vertical-horizontal illusion, but this would not explain the sex differential, the virtual absence of angle overestimation by males, and the dramatically greater amount of the illusion in the other experimental situations.

The probable irrelevance of head tilt for the slope and angle judgments is also not a compelling reason to classify them separately, although head tilt may remain a unique, contributing factor. An alternative explanation of the illusion covering all of the cases might be based on a transactional or behavioral coding of the visual cues for distance and length. For example, it is possible that when, in the past, visual cues have involved head tilt up or down or involved directly perceived slope, they have represented targets which required more effort to reach and were thus coded in motor-effort units as being farther away.

\section{The Moon Illusion}

The data clearly show that not Emmert's law but, if anything, its reverse holds for afterimages in the sky. Kaufman and Rock (1962) and Woodworth and Schlosberg (1954) have admitted, while subscribing to Emmert's law in the situation, that the moon itself is typically experienced as not only larger, but also as closer, in its horizon setting. This phenomenal finding is explained away as a secondary effect, a result of the size illusion itself.

To understand this apparently perverse loyalty to Emmert's law in the face of contradictory data, it may be noted that the moon's image and the afterimage are alike in two respects: they both have a constant retinal size, and they both lack the ordinary visual cues to distance (except for cues that should indicate that they are not nearby). It is only parsimonious that if Emmert's law describes size and distance judgments for afterimages it should also cover size and distance judgments for the moon.

On the other hand the demonstration that the larger appearing horizon moon must also (unconsciously) appear to be farther away as Emmert's law demands has not been accomplished. What Kaufman and Rock 
have shown, for example, is that a visual context of earthly terrain contributes to an apparently larger moon, but if and how this visual terrain produces a hypothetically increased apparent distance remains to be shown. The one point offered to support the flattened sky assumption is that observers typically aim too low when asked to point out an elevation of $n$ degrees (from 0 to 90 ) above the horizon. Since this fact can be seen to be simply another case of perceptual overestimation of vertical distance and slope, it is obvious that several well chosen assumptions are necessary to convert it into support for an opposite conclusion (see Kaufman \& Rock, 1962).

There is an interesting alternative to Emmert's law in understanding the size-distance interaction in these cases which was first suggested to the $\mathrm{E}$ by the spontaneous statements of a few of the Ss participating in the experiment on afterimages (Experiment 6). These students commented to the effect that "Of course if it is closer it should be larger," with the words "closer" and "larger" sometimes interchanged. This kind of statement is indeed a description of general daily experience, but only if the observer shifts the locus of his size judgments from external objects to retinal images, for it is the retinal image which becomes larger when an object is moved closer. To make this kind of statement the observer must abandon the assumption or construction of size constancy and behave like an introspectionist, although his choice of words hides this fact.

If an observer can report changes in his retinal image size then it is also conceivable that he would suffer from biases in his judgment of them. For example, if he assumed that the moon and sky afterimages were like solid objects of constant physical size, then he would expect a decrease in perceived distance to be accompanied by an increase in (retinal) size. Thus his verbal statement of the relationship might correspond with the perceptual expectancy mechanisms at work. The advantage of considering this position is that it is consistent with the data and does not postulate contrary unconscious processes, or involve the assumption that the sky is perceived as a surface, whose distance is somehow biased by the visual terrain.

None of this rules out the possibility that both the size and distance illusions could be simultaneous byproducts of some third factor, such as vestibular stimulation. Until more data are collected, however, it is difficult to specify how such simultaneous biases might arise and operate.

\section{References}

Kaufman, L., \& Rock, I. The moon illusion, Scient. American, $1962,207,120-130$

King, W. L., \& Gruber, H. E. Moon illusion and Emmert's Law. Science, 1962, 135, 1125-1126.

Thor, D. H., \& Wood, R. J. A vestibular hypothesis for the moon illusion. Paper presented to the Annual Meeting of the Midwestern Psychological Association in Chicago, May 5, 1966.

Woodworth, R. S., \& Scholosberg, H. Experimental psychology. Henry Holt, 1954.

\section{Notes}

1. Now on a one year's leave of absence to Bell Telephone Laboratories, Inc., Holmdel, New Jersey.

2. Emmert's law states that the apparent size of an afterimage is directly proportional to its apparent distance from the observor.

(Accepted for publication August 16, 1967.) 